\title{
Online College Education For Computer-Savvy Students: A Study Of Perceptions And Needs
}

Belal A. Kaifi, University of San Francisco, USA

Bahaudin G. Mujtaba, Nova Southeastern University, USA

Albert A. Williams, Nova Southeastern University, USA

\begin{abstract}
With new technologies and cyberspace-literate students, distance education has been in high demand and more schools are getting into online education. As such, understanding the needs of current and prospective learners has become especially important for success in the new millennium. Based on the learners' needs and current technology status, this study provides a review on the feasibility of online education for modern students in a developed nation. Based on the survey of 203 undergraduate students, this research provides an assessment of their views, needs, and wants for the feasibility of offering online courses and programs. Such demographic variables as gender, ethnicity and education demonstrated statistically significant results. Recommendations are provided for administrators to enhance their online offerings as a result of the feedback from students. The document further explores online education, online operation, and other such variables that impact the success of students in higher education.
\end{abstract}

Keywords: Online education, distance learning, gender, computers, assessment, and curriculum development

\section{INTRODUCTION}

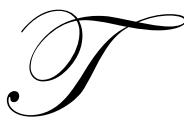

he twenty-first century is the first century of comprehensive worldwide online learning both academically and for workforce training (Mujtaba, 2008; Mujtaba \& McAtavey, 2006). The business of higher education has become very competitive as schools move far beyond their main campuses to offer programs nationally and internationally. Learners need not be concerned about the modality of the education programs since many of the same educators who facilitate in the traditional programs are also now teaching at distance education programs (Mujtaba \& McAtavey, 2006). As such, the quality and outcomes achieved are likely to be the same for all programs (Mujtaba, Preziosi \& Mujtaba, 2004). Assessment studies indicate that learning in distance and online education are at least equal to that in traditional classes, if not better (Hannum et al., 2008, p. 223; Mujtaba \& McAtavey, 2006).

Most schools are now well equipped and can easily integrate online education in their existing programs. Some experts believe that "The technical infrastructure prerequisite to e-tutoring is widely available in schools and institutes of higher learning" (Johnson \& Bratt, 2009, p. 33). Cyberspace technologies are now complimenting all learning formats. "With regard to technologic tools, faculty and students alike identified the importance of using multiple tools appealing to diverse learning styles" (Menchaca \& Bekele, 2008, p. 247). Others say that "the greatest growth and use of online learning is at the tertiary level, the impact of distance education is also being felt in secondary schools" (Hannum et al., 2008, p. 211). Hannum et al. also mention that "The incidence of distance education in high schools in rural areas of the USA is higher than the national average" (2008, p. 212). People are continuing to study cyberspace learning and modalities as "Distance education and related research has continued to proliferate" (Menchaca \& Bekele, 2008, p. 231). Faculty members and administrators are still trying to find the right mix of technologies and approaches for achieving student learning outcomes (Mujtaba \& Mujtaba, 2004). According to research, "Taken together, that both infrastructure and tools were crucial for success reflected a highly contextual 
nature for online learning environments" (Menchaca \& Bekele, 2008, p. 234).

Just like everything else, there is a learning curve for online education. Administrators, faculty members and students need time and practice with new technologies in education. Due to their diversity and lack of face-toface interaction opportunities, online students do face challenges and difficulties in their learning (Mujtaba, 2005; Mujtaba \& Scharff, 2007). Some of these challenges are related to clarity of course materials, course organization, discipline, group dynamics, level of feedback not being sufficient or timely, and other technical difficulties with the platform being used. "The more experienced the students and instructors were, the better their success" (Menchaca \& Bekele, 2008, p. 234-235). "A report by the US Department of Education (2007) found that school districts that are using online courses, as well as providers of these courses, indicate that the more support students receive at school, as well as online, the better chances they have for success" (Hannum et al., 2008, p. 212). Also, "The level of administrative support available to students and instructors was also crucial" (Menchaca \& Bekele, 2008, p. 235). Therefore, benchmarking and teamwork becomes key in avoiding mistakes. Experts suggest that "Program teams are recommended to explicitly share common practices and knowledge" (Correia \& Davis, 2008, p. 303).

Some educators are using technology to stay in contact with their students and provide them more resources as to accommodate their learning needs and interests. Today's students tend to be successful as most programs are well supported through orientation for online learning, multiple points of contact for course resources, and frequent and regular feedback for student learning (Mujtaba, 2005). According to Hannum et al. (2008, regular contact with learners during the semester increased the number of students successfully completing the course. Hannum et al. continues to write that:

Many distance education courses push content to learners via the Internet, but fail to provide students with necessary support for learning. Having someone physically present with the learner, who knows the learner and fully understands the local context of the learning, can be beneficial. Many distance education courses ignore this human element. Likely, this is why so many students drop out of distance education courses and rate them poorly. Important pieces essential for learning are missing, and students recognize this. (Hannum et al., 2008, p. 213)

However, the focus in designing online platforms and e-learning environments should not be solely on technologies and single tools or media. Wahlstedt et al., write that:

Working environments differ, learners' preferences differ and the requirements of the subject matter differ. Instead of designing from technological foundations, the designers of e-learning environments should act as architects, comprehending the environment as a place for learning rather than a collection of different technologies. (Wahlstedt et. al., 2008, p. 1029)

Some administrators are sending their faculty members and staff to other schools for acquiring best practices. For example, "The engineering schools of five U.S. universities are poised to send faculty members to India as a part of a distance learning initiative undertaken by the Indian government and Amrita University" (Fortner, 2005, p. 28). Often, such travels have specific objectives for the team's learning and development. Fortner mentions that:

The goal of the program is to provide the best education possible for students in India, to give professors in the United States a better understanding of the learning tools and technologies used abroad, and to recruit Indian students to study in the United States. (Fortner, 2005, p. 28)

Another important element is that educators and students need to identify each other's teaching and learning styles. According to Smith (2008), "the need to work with others through text-based online environments can make trust issues more salient" (p. 325). "Yet, it is difficult to answer the question of how trust is developed and maintained within these groups and how trust issues influence collaborative processes and outcomes" (Smith, 2008, p. 325). It should be acknowledged that both trust and mistrust tend to be on the opposite ends of a relationship continuum between students and educators. Yes, students and educators "need to live with the fact that there will always be both trust and mistrust" (Smith, p. 336). When there is a high level of trust between educators and learners, then "The space becomes a place as it has genuine meaning, fulfilling a certain purpose in people's lives. If 
the purpose can be harnessed to learning, the likelihood that learning will take place will increase" (Wahlstedt et. al., 2008, p. 1029).

Overall, there has been much written about the use of advanced technology in higher education and how best to use that technology in the teaching-learning process, but little research is done each year in most programs to survey the students' needs, wants and their overall perceptions with the operation. As such, some programs lose students who really want to finish their degrees through this format of distance education. According to Terry (2001), researchers have found that while online courses enrolled more students compared to on-ground courses, online courses lost more students to attrition than on-ground (Mujtaba, 2005). Distance education holds great promise for schools and adult students but the attrition problem is a concern. Many higher education schools have similarly reported that their online education students have higher attrition rates than on-ground classroom students. Researchers, academicians and administrators do agree that there is a need for more research about this attrition problem (Henke \& Russum, 2000; Mujtaba \& Scharff, 2007). A starting place for more research is to assess the requirements of future online students and determine their capability with regard to technology used for online education. The purpose of this article is to evaluate the needs and expectations of future online students and determine their preferences with various elements of the online program. Special attention is paid to such factors as software used, chat sessions, course design, technology, and the learning environment. Also, there is a review of the characteristics needed for an ideal learning environment with technologically savvy learners.

Distance education. According to researchers (Mujtaba, 2005; Eastmond, 1998), the term distance education has become synonymous with instruction and facilitation provided through cyberspace technologies via the Internet. As such, many such programs are commonly referred to as online education. Some believe that:

Online education embodies a shift away from traditional, classroom-based teaching activities typically associated with university education toward a technological realm where teaching requires the use of computers equipped with specialized course software systems, both synchronous and asynchronous computer applications, and the frequent frustrations associated with dependence on the Internet. (Gibson et al., 2008, p. 355)

Mujtaba (2005) and Eastmond (1998) discussed three different types of Internet-based courses: first, there is the distance learning programs which are supplemented by use of Internet technologies as a support mechanism as opposed to being the primary medium of delivery; second, there is the computer conferencing medium where Internet is the primary delivery utilizing asynchronous discussions and emails; third, there is the virtual course from the virtual institution where all or most aspects of the course are delivered online. As a matter of fact, experienced and skilled online facilitators are able to use colorful graphics, audio and video streams, and hypertext links to bring out the learning as well as to involve the various senses of learners to increase their understanding. With a teachinglearning process in the online world, adult students are expected to be actively involved in the knowledge generation process while interacting with the instructor and their colleagues about the material to be learned as guided by the faculty. Faculty members make the difference in student learning as their facilitation skills can be geared toward truly learning or simply having students memorize so they can pass an exam. Online faculty members should involve students in the learning process through their formal and informal facilitation since their involvement can lead to real learning, application and long-term retention. As such, the faculty serves as a facilitator in the learning process as is the case in many of today's non-traditional schools and adult training sessions in the workforce rather than being the primary transmitter of knowledge. This is even more important in the online environment if the material is to be learned, utilized and retained by the graduates of a course or program. "Although schools are embedded in this technological culture, the education system is largely unchanged. In other words, students are far more technologically savvy than the institutions that support them" (Desai et al., 2008, p. 329). According to Desai et al., "The 1990's brought online improvements with the introduction of specifically designed courses management systems which adopted a collaborative learning approach" (2008, p. 330). They further mention that:

E-learning requires great maturity and disciple compared to traditional learning. It demands that learners interact and collaborate which is not always the case in traditional learning. This type of learning can result in a deeper understanding and is usually preferred by adult learners. (Desai et al., 2008, p. 331) 
Distance education courses and programs using online teaching modalities can enhance a school's offering. Some believe that "For universities and colleges, online education provides the opportunity to serve more students who desire an education" (Gibson et al., 2008, p. 356). Regardless of teaching modality, "Faculty are intrinsically motivated to help students, but extrinsically motivated to meet their physiological needs through incentives" (Cook et al., 2009, p. 150). Cook et al., explain that "The success of electronic, web-based, courses (e-courses) depends not only upon the schools and universities, but also on the faculty and adjunct instructors who teach these courses"(2009, p. 149). Offering them distance learning technologies will make it easier for faculty to meet the learning needs of their students. Today, having advanced technology is not such a luxury but rather a necessity for survival and remaining competitive:

As in other organizations, university administrators frequently view these technological changes as being a requirement for providing one's product or service on demand, reaching a broader demographic, and sustaining one's competitive advantage in an increasingly competitive market. However, despite the perceived necessity of new and sophisticated technology, the end users of such technology may not readily embrace such tools. (Gibson et al., 2008, p. 355)

Some faculty members tend "to express apprehension regarding online education because of the technological problems associated with delivering the material, which may lead to student frustration and poor student evaluations" (Gibson et al., 2008, p. 356). However, as stated by Gibson et al., "With the increasing demand for online education and the need for faculty to embrace this as a viable teaching tool, user acceptance of technology based teaching is an important issue" (2008, p. 356). Distance education is extremely critical for efficiently and economically accommodating the learning styles of diverse students while meeting their needs and wants. Research shows that:

Sixty seven percent of colleges and universities agree that online education is the single significant development and logical long-term strategy for the field of teacher preparation, offering flexibility and convenience by providing learning opportunities to anyone, at anytime, and anywhere. (Shin \& Lee, 2009, p.33)

Distance education is especially advantageous because it makes learning accessible to students all day, everyday, giving them immense control over their own learning schedules" (Chang \& Smith, 2008, p. 407). In all cases, facilitators and educators must stay focused on student learning. Chang and Smith explain that "Course satisfaction is a critical component in improving learning achievement in the traditional classroom and the distance education environment" (2008, p. 412). Course satisfaction is about managing the learning effectively. Some claim that "Perhaps the most distinguishing attribute of an online design model that makes use of course management systems is reliance on the group discussion board where students are either encouraged or mandated to initiate and respond to posted questions" (Norton \& Hathaway, 2008, p. 479). The key about facilitation is getting the learners involved in the process since "research about the implications of interaction on student learning has identified that interaction positively affects students' abilities to learn" (Chang \& Smith, 2008, p. 412). Johnson and Bratt write that students can get personal attention since "Electronic tutoring (E-tutoring) or Internet tutoring (I-tutoring) refers to individualized learning support provided via the Internet and includes ongoing communication between e-tutor and e-tutee" $(2009$, p. 33). What is a fact is that "The majority of college students today have grown up with the Internet, e-mail, and instant messaging. In their culture of instant gratification, students seek immediate feedback on assignments and demand access to grades and class materials" (Jackson \& Helms, 2008, p. 7). According to Jackson and Helms, "Concern for quality in learning programs is at an all-time high, but there remains no clear definition of what this quality encompasses" (2008, p. 8). Educators are also concerned about the time it takes to facilitate online courses as "Instructors have found that it is more difficult to assess learner achievement in e-learning. Part of the problem is the lack of resources to help instructors assess and improve online courses" (Desai et al., 2008, p. 331). Most researchers have agreed that "Instructors find that e-learning is much more labor-intensive and they have to acquire unusual skills, experience, and dedication to be successful than comparable traditional learning" (Desai et al., p. 331).

Teaching vs. facilitating. Besides technology and computer-literate students, the economy also has a huge impact on education as today's administrators are faced with a daunting challenge of keeping their schools running during these recessionary times in the United States and many places abroad. As the economy has gotten worse, the 
classrooms are increasingly more crowded and the teachers are given fewer resources to achieve their tasks meeting each course's learning outcomes. The challenge for administrators and faculty members will be to find effective ways to engage students in the learning process in most cost effective manners. As mentioned by Mujtaba, Preziosi and Mujtaba (2004), student engagement is the key to learning in both on-ground and online courses. Online and distance learning classes can provide effective facilitation opportunities between the learner, learner/instructor, and the course exit competencies as they can be linked to daily happenings. However, "Distance educators have had to redefine their communication skills. They have found that two-way interaction is a critical feature of the educational process. Educators must communicate progress to learners as well as engaging the learners into the e-learning environment" (Desai et al., 2008, p. 328). According to Desai et al., "For distance education to be successful, high levels of interaction typically need to be present for learners to have positive attitudes and greater satisfaction" (2008, p. 328). Furthermore, "There has to be a certain amount of structure in distance education that fosters a certain amount of dialogue between the learner and instructor" (Desai et al., p. 328). As we know, "Many students today experience their college coursework while simultaneously managing their careers, households, as well as personal lives" (Notar et al., 2008, p. 123). Notar et al., (2008) write that "The best method for reaching this changing student body, and for addressing their learning needs, it to provide them with the resources to practice and review course materials independently" (p. 123). It is believed that "With the advancement of the Internet, educators have an unmatched opportunity to design and conduct effective distance learning courses filled with helpful features that promote communication and interaction" (Chang \& Smith, 2008, p. 412). It must be emphasized that:

Educators must understand that utilizing these advanced technologies will not automatically make their distance learning courses more dynamic and interactive. In fact, more hard work is required by the instructor to effectively adapt the technologies to develop clear, interactive online courses. (Chang \& Smith, 2008, p. 412)

Regardless of whether courses are delivered in traditional face-to-face format or online modalities, the educator's job is to facilitate the content with the available tools in every given situation. There are some practical reflection points that one should remember when facilitating content to learners. While teaching is relevant in some cases, a better approach is to mix teaching with facilitation to create a more effective learning environment for all students (Mujtaba and Mujtaba, 2004). As explained by Cornwell (2009), some of the differences between being a "teacher" in the classroom and being a "facilitator" can include the following:

- A teacher is one who tells learners what they need to know. A facilitator asks the questions that aids in the discovery and learning process.

- A teacher lectures. A facilitator supports active learning and discussion with the learners.

- A teacher provides the answers. A facilitator provides learning guidelines and creates a learning environment.

- A teacher is one who engages mostly in a monologue. A facilitator creates continuous dialogue and is willing and able to adapt the learning experience in "mid-air" to meet the needs of the students.

Therefore, all educators should strive to be less of a "teacher" and more of a "facilitator" in their education opportunities of face-to-face and cyberspace classrooms.

\section{METHODOLOGY AND DEMOGRAPHICS}

The purpose of this is research, based on the survey of undergraduate students, is to provide an assessment of the learner's views, needs, and wants for an online program. The goal is to provide recommendations for administrators to enhance their online offerings as a result of the feedback from students. Some of the research questions regarding feasibility of online education for this study are as follows:

1. Is there a gender or ethnicity effect in computer usage and ownership?

2. Do all students own a computer?

3. Do students use computers on a daily basis?

4. Do online students use computers from home or work? 
The survey was distributed to 250 undergraduate students. A total of 203 surveys were filled out correctly and entirely which could be used for this study. Students were from various departments: Medical Assisting (43), Pharmacy Technician (70), Nursing (9), Dental Assisting (10), Criminal Justice (57), Health Information Technology (4), and Massage Therapy (10). Their education levels were as follows: second year of college (40), and first year of college (163). Of the total respondents, 118 were female and 85 were male. There were fifty-five Caucasian, fifty-five African- Americans, forty-seven Hispanics, eleven Asians, twelve Native Indians, and twentythree participants who claimed "other" as their ethnicity. Out of the total participants, 135 were between the ages of 17-25, another 67 were between the age of 26-35, and only one participant was between the ages of 46-55. This reflected the typical younger student body at the institution studied. Furthermore, 95 respondents were currently unemployed, one person has been employed for the last 6-15 years, 63 participants have worked 1-5 years, and 44 participants have worked for less than one year.

\section{STUDY ANALYSIS AND RESULTS}

This research looked at how demographic factors impacted online education. There were fifteen dependent variables, representing online education, and six independent variables representing demographic factors. Table 1 shows the dependent and independent variables for this study.

Of the 203 participants, 163 had completed only high school education and 40 of them had completed their college degrees. Ninety five participants were unemployed (full time students), 44 of them had less than one year at their present job, 63 of them had one to five years at their present place of employment, and one of them had six to fifteen years at their place of employment. Seventy of the participants were in the pharmacy technician program. Fifty seven of them were in the criminal justice program while forty three of them were in the medical assisting program. Also, there were 10 participants in the dental assisting program, 9 in nursing, etc.

Table 1 - Variables Representing Online Education and Demographic Factors

\begin{tabular}{|l|l|l|}
\hline & \multicolumn{1}{|c|}{ Dependent variables } & \multirow{5}{*}{ Independent Variables } \\
\hline Q1 & Frequency of Computer Use & \multirow{3}{*}{ Age, Race, Education, Work Experience and School Program } \\
\hline Q2 & Computer Ownership & \\
\hline Q3 & Own Internet Service & \\
\hline Q4 & Internet Access Location & \\
\hline Q5 & Computer Proficiency & \\
\hline Q6 & Internet Proficiency & \\
\hline Q7 & Motivation for Independent Study & \\
\hline Q8 & Time for Online Study & \\
\hline Q9 & Time Management Skills & \\
\hline Q10 & Online Course Experience & \\
\hline Q11 & Online Class Option & \\
\hline Q12 & All Classes Online & \\
\hline Q13 & Online Group Work & \\
\hline Q14 & Biggest Concern for Online Study & \\
\hline Q15 & Preference for Computer Lab and Tutors on Campus & \\
\end{tabular}

With regards to online study capability, fifteen questions were asked. The first question was about the frequency of computer usage for each participant. One hundred and thirty participants used the computer every day, 39 used it every other day, 10 used it once a week and 24 responded other. The second question was about computer ownership. One hundred and fifty five participants (76 percent) owned a computer. The third question was about having Internet access. One hundred and fifty eight participants had their own Internet service provider. The fourth question was about place of access for online class. Ninety three said they access online courses from home, 55 from school, 6 from the office, and 49 from both home and school. The fifth question was about proficiency with computers. Two had no computer training, 11 were below average, 110 were average, 51 were above average, and 29 were excellent. The sixth question was about proficiency with the Internet. Two had no training, 4 were below average, 104 were average, 50 were above average, and 43 were excellent. The seventh 
question was about motivation and ability to work independently. One hundred and sixty seven stated that they were capable of working independently. The eighth question was about having enough time to do online study. One hundred and twenty four stated that they had enough time to do online study. The ninth question was about time management skills and 10 had none, 28 were below average, 96 were average, 46 were above average, and 23 were excellent. The tenth question was about taking online class before and thirty three participants said they did. The eleventh question was about having the option to take classes online, where one hundred and eighteen stated that they would like the option to take online classes. The twelfth question was about taking all classes online and only 59 participants wanted to take all classes online. The thirteenth question was about doing group work in an online setting and ninety three participants stated that they would be willing to do group work online. The fourteenth question was about the biggest concern in online education. Forty six stated that they would not learn as much, 59 were concerned about no face-to-face interaction, 38 were concerned about no support from institution, 19 were concerned about no frequent feedback, and 41 were concerned about too many distractions. The fifteenth question was the effectiveness of an online program if there was a computer lab and tutors on campus. One hundred and forty seven participants responded yes to this question.

A correlation analysis was done for all variables. The six demographic variables, to be used as independent variables, had low correlation coefficients (less than 0.35 ). The fifteen online education variables also had low correlations, except for Question 2 (computer ownership) and Question 3 (own Internet service provider), and Question 5 (computer proficiency) and Question 6 (Internet proficiency). Question 2 and Question 3 had a correlation of 0.5403 . This was not surprising as Question 2 is about owning a computer and Question 3 was about having an Internet service provider. It is common for those who own computers to have an Internet service provider. Question 5 and Question 6 had a correlation of 0.6275. This again was not surprising as Question 5 was about proficiency with computers and Question 6 was about proficiency with the Internet.

Multiple regression analyses were done for all fifteen dependent variables. The independent variables were: Age Group, Race, Education, Work Experience, and School Program. The independent variables were tested for multi-collinearity using a variance inflation factor (VIF) test. All estimates were approximately 1 , which were much lower than the usual benchmark of 5 .

The first dependent variable, Frequency of Computer Use, was significantly related to the independent variables Education and Employment (see Table 2). The variable, Education, had a beta coefficient of 0.365 and a p-value of 0.048. This result was reasonable as we expect more educated people to utilize the computer more frequently. The next variable, Employment, had a beta coefficient of -0.101 with a p-value of 0.101 , which is marginally significant at the 10 percent level. This implied that the unemployed used the computer more often. This was not a surprising result as the unemployed were full-time students.

The second dependent variable, Computer Ownership, was related to Ethnicity, which had a beta coefficient of 0.043 and a p-value of 0.031 . This implied that American Indian/Native Americans and the Other category tended to have fewer computers than White and Black Americans. Hispanics were ranked in the middle of the group.

The third dependent variable, Own Internet Service Provider, was significantly related to Ethnicity and Employment. Ethnicity had a beta coefficient of -0.033 and a p-value of 0.099 . This finding was a spin-off from the significant relationship found between computer ownership and ethnicity. Note that there was a high correlation between computer ownership and own Internet service. The next independent variable, Employment, had a beta coefficient of -0.049 and a p-value of 0.054 . This result implied that the unemployed (full-time students) had their own Internet service as well as those who had jobs for a longer period of time. It was very likely that full-time students were younger and included their own Internet service as a necessity or they lived at home with their parents who bought the Internet service.

The fourth dependent variable, Internet Access Location, was significantly related to Age Group, Education, and Employment. Age Group had a beta coefficient of -0.278 with a p-value of 0.106 . This implied that younger participants accessed their online class from home and from school. Education had a beta coefficient of 0.503 and a p-value of 0.022 . Younger participants connected to the internet from home and school. The older 
participants connected from work. Employment had a beta coefficient of 0.153 with a p-value of 0.037 . Participants with fewer years at work connected from home or school. Participants that worked for more than 5 years connected to the Internet from home and work.

The fifth dependent variable, Computer Proficiency, had one significant independent variable, Employment. This variable had a beta coefficient of -0.090 with a p-value of 0.080 . This implied that the unemployed, those that had jobs less than a year, and those that had jobs from 1 to five years were more computer proficient than those with employment from 6 to 15 years. This was not a surprising result, considering that younger people tend to be more computer savvy.

The sixth dependent variable, Internet Proficiency, was significantly related to Age Group, Ethnicity, and Employment. Age group had a beta coefficient of -0.352 and a p-value of 0.004 . This result showed that younger participants were more Internet savvy than older ones, a reasonable result. The variable, Ethnicity, had a beta coefficient of 0.073 and a p-value of 0.067. This implied that White and Black Americans were more Internet proficient than American Indian/Alaskan Natives and the Other category. This result was linked to computer ownership, and computer proficiency. The variable, Employment, had a beta coefficient of -0.089 and a p-value of 0.083. This result implied that the newly employed and the unemployed were more Internet proficient than those with six or more years of employment. This result was similar to that for computer proficiency.

The seventh dependent variable, Motivation for Independent Study, was significantly related to Age Group, Ethnicity, and Employment. Age Group had a beta coefficient of 0.100 with a p-value of 0.063 . This implied that the younger participants were more motivated to do online independent study than the older participants. Ethnicity had a beta coefficient of -0.056 with a p-value of 0.002 . This result implied that White and Black Americans were more motivated to do independent online study than did American Indian\Alaskan Native and those in the Other category. Employment had a beta coefficient of -0.041 with a p-value of 0.075 . This implied that those that were recent hire were less motivated than those who had jobs for more than five years. Perhaps, those with more years of employment had a more urgent need to upgrade their education, perhaps to be promoted.

The eighth dependent variable, Time for Independent Study, was significantly related to Employment. Employment had a beta coefficient of 0.052 with a p-value of 0.076 . This implied that those with more years of employment had more time for independent study.

The ninth dependent variable, Time Management Skills, was significantly related to Age Group. Age Group had a beta coefficient of -0.279 with a p-value of 0.051 . This implied that younger participants stated that they had better time management skills than did older participants - an interesting result.

The tenth dependent variable, Online Course Experience, was significantly related to Gender and Education. Gender had a beta coefficient of 0.093 with a p-value of 0.079 . This implied that males had more online course experience than did females. Education had a beta coefficient of -0.135 with a p-value of 0.047 . This implied that the participants with two years or more of college education had more experience with courses online.

The eleventh dependent variable, Online Class Option, was significantly related to Employment. Employment had a beta coefficient of 0.063 with a p-value of 0.038 . This implied that those that were recently hired preferred to have the option of online classes as compared to those with much longer periods of employment.

The twelfth dependent variable, All Class Online, was related to Gender and Age Group. Gender had a beta coefficient of 0.123 with a p-value of 0.059 . This implied that males preferred to have all their classes online compared to females. Age Group had a beta coefficient of -0.135 with a p-value of 0.038 . This implied that the younger participants preferred to have all their classes online than did older participants.

The thirteenth dependent variable, Online Group Work, was significantly related to Gender, Age, and Education. Gender had a beta coefficient of 0.123 with a p-value of 0.083 . This implied that more males were willing to work in online group than did females. 
The fourteenth dependent variable, Biggest Concern for Online Study, did not show up as significantly related to the demographic variables. This was a surprising result.

The fifteenth dependent variable, Preference for Computer Lab and Tutor on Campus, was significantly related to Ethnicity, Education and Program. Ethnicity had a beta coefficient of -0.042 with a p-value of 0.041 . This implied that White and Black Americans preferred to have a computer lab and tutor on campus than did American IndialAlaskan Native and the Other category. Education had a beta coefficient of -0.207 with a p-value of 0.009. This implied that those who acquired less education preferred these facilities than those with more education. Those with more education were older and probably would not come to campus as often. The independent variable, Program, had a beta coefficient of 0.050 with a p-value of 0.013 . Those in the Pharmacy Technician and Criminal Justice programs preferred these facilities than those in the Dental Assisting and Nursing programs.

Overall, the demographic variables were significant (see Table 3). Gender showed up as significant in 4 of the 15 multiple regression analyses. Age Group was significant in 7 regression estimations. Ethnicity was significant in 5 regression estimations. Education was significant in 6 regression estimations. Employment was significant in 8 regression estimations and Program was significant in only 1 regression estimation.

\section{CONCLUSIONS AND IMPLICATIONS}

As everyone knows, simply gathering data or knowledge without actually making incremental improvements in the operation and enhancing the program is useless. Many individuals have traditionally claimed that "knowledge is power" when in reality that is not really always the case since it is the appropriate use and application of knowledge that can generate power. For example, a person who knows how to read but does not ever read (relevant and useful) material is probably not much better than a person who does not know how to read. So, it is the effective use and timely application of knowledge and abilities that can lead to incremental and radical improvements. The findings of this research demonstrate the needs and wants of current and prospective college students. Therefore, administrators and faculty members could use it to enhance their offerings and student learning. The more successful a school's online students, the better the school's marketing will be through word-of-mouth by existing students and alums.

The widespread existence of new technologies has put distance education in high demand and more schools are getting into online education. As such, this study focused on understanding the needs of current and prospective learners. Understanding the common denominator of technology available to students can assist administrators and faculty members design their admission, teaching and curriculum requirements. This research, based on the survey of undergraduate students, provided an assessment of their views, needs, and wants for online distance education programs. Overall, the analysis demonstrated that the demographic variables were significant. For example, gender showed up as significant in several of the multiple regression analyses. Age Group, Education and Ethnicity were significant in several regression estimations. Also, Employment was significant in several regression estimations and Program was significant in one regression estimation. Consequently, administrators can enhance their online offerings as a result of the feedback from students and positively impact the success of learners in higher education. While not all online students own a computer or use computers on a daily basis, it appears that they are able to get their work done using personal, work or school computers. Therefore, all students should be able to successfully access online courses and schools should make these options available as to better accommodate learning styles and travel schedules of working adults.

\section{AUTHOR INFORMATION:}

Belal A. Kaifi earned a doctorate degree from the University of San Francisco where he is studied and researched organization and leadership in the School of Education. Belal teaches undergraduate and graduate level courses in Business Administration and Global Issues at Franklin University. Belal can be reached at: belalkaifi@yahoo.com.

Bahaudin G. Mujtaba is an Associate Professor of Management, Human Resources, and International Management at Nova Southeastern University's H. Wayne Huizenga School of Business and Entrepreneurship in Fort Lauderdale, Florida. Bahaudin has worked as an internal consultant, diversity trainer, and management 
development specialist as well as retail management in the corporate arena for over twenty-five years. Bahaudin is the author and co-author of several books in the areas of cross-cultural management, business ethics, education, and change management. Bahaudin can be reached through email at: mujtaba@ nova.edu.

Albert A. Williams is an Assistant Professor and has been teaching at Nova Southeastern University in both graduate and undergraduate programs in finance, economics and business statistics. Before returning to academia, he was a commodity analyst at Restaurant Services Incorporated in Miami, Florida. In Belize, he was the chief executive officer of the Belize Marketing Board. In addition, he was an agricultural economist for the Government of Belize. He also was a project officer at the Development Finance Corporation in Belize. Prior, Albert was a mathematics professor in Belize. Albert can be reached at albewill@nova.edu.

\section{REFERENCES}

1. Chang, S.H., \& Smith, R.A. (2008). Effectiveness of personal interaction in a learner-centered paradigm distance education class based on student satisfaction. Journal of Research on Technology in Education, 40(4), p. 407- 426.

2. Cook, R., Ley, K., Crawford, C., \& Warner, A. (2009). Motivators and inhibitors for university faculty in distance and e-learning. British Journal of Educational Technology, 40(1), p. 149-163.

3. Cornwall, Jeff. Becoming a Classroom Facilitator - Entrepreneurship Education Newsletter. The Entrepreneurship Educator, February 09. Received on February 18, 2009 from: newsletter@planningshop.com

4. Correia, A., \& Davis, N. (2008). Intersecting communities of practice in distance education: the program team and the online course community. Journal of Distance Education, 29 (3), p. 289- 306.

5. Desai, M., Hart, J., \& Richards, T. (2008). E-learning: Paradigm shift in education. Education, 129(2), p. 327-334.

6. $\quad$ Eastmond, D. (1998). Adult learners and Internet-based distance education. New Directions for Adult and Continuing Education, 78, 33-41.

7. Fortner, B. (2005). U.S. universities sign distance learning education contract with India. Civil Engineering, 75 (11) p. 28.

8. Gibson, S., Harris, M., \& Colaric, S. (2008). Technology acceptance in an academic context: Faculty acceptance of online education. Journal of Education for Business, 83(6), p. 355-359.

9. Hannum, W.H., Irvin, M.J., Lei, P., \& Farmer, T.W. (2008). Effectiveness of using learner-centered principles on student retention in distance education courses in rural schools. Distance Education, 29 (3), p. 211-229.

10. Henke, H. \& Russum, J. (2000). Factors influencing attrition rates in a corporate distance education program. Education at a distance, 14 (11), Article 03. Retrieved July 25, 2001 from http://www.usdla.org/ED_magazine/illuminactive/ NOV00_Issue/ story03.htm

11. Jackson, M.J., \& Helms, M.M. (2008). Student perceptions of hybrid courses: Measuring and interpreting quality. Journal of Education for Business, 84(1), p. 7-12.

12. Johnson, G.M., \& Bratt, S.E. (2009). Technology education students: e-tutors for school children. British Journal of Educational Technology, 40(1), p. 32-41.

13. Menchaca, M.P. \& Bekele, T.A. (2008). Learner and instructor identified success factors in distance education. Distance Education, 29(3), p. 231-252.

14. Mujtaba, B. G. (2008). Interpersonal Change through the "Inside-Out-Approach": Exercising the Freedom to Choose Our Responses during Conflict and Stressful Situations. RU International Journal, 2(1), 1-12.

15. _ (2005). Faculty Development Practices in Distance Education for Success with Culturally Diverse Students. International Business and Economics Research Journal, 4(4), 1-13.

16. _ and McAtavey, J. (2006). Performance Assessment and Comparison of Learning in International Education: American versus Jamaican Students' Learning Outcomes. The College Teaching Methods \& Styles Journal, 2(3), 33-43.

17. _ and Mujtaba, L. (February 2004). Creating a Healthy Learning Environment for Student Success in the Classroom. The Internet TESL Journal, X(2). The article can be retrieved via the following URL link: http://iteslj.org/ or: http://iteslj.org/Articles/Mujtaba-Environment.html. 
18. _ _ and Mujtaba, L. (2004). Diversity Awareness and Management in Adult Education. Journal of College Teaching and Learning. 1(3), 65-75.

19. _ _ Preziosi, R., \& Mujtaba, L. (2004). Adult Learning, Assessment, and the Extraordinary Teacher. Journal of College Teaching and Learning. 1(4), 29-37.

20. _ _ _ and Scharff, M. M. (2007). Earning a doctorate degree in the $21^{\text {st }}$ century: Challenges and joys. ILEAD Academy Publications; Florida, USA.

21. Neely, L., Niemi, J. \& Ehrhard, B. (1998). Classes going the distance so people don't have to: Instructional opportunities for adult learners. T.H.E. Journal, 26(4), 72.

22. Norton, P., \& Hathaway, D. (2008). Exploring two teacher education online learning designs: A classroom of one or many? Journal of Research on Technology in Education, 40 (4), 475- 495.

23. Notar, C., Herring, D., \& Restauri, S. (2008). A web-based teaching aid for presenting the concepts of norm referenced and criterion referenced testing. Education, 129 (1), p. 119-124.

24. Poole, D. (2000). Student participation in a discussion-oriented online course: A case study. Journal of Research on Computing in Education, 33 (2), 162-77.

25. Richards, C. \& Ridley, D. (1997). Factors affecting college students' persistence in online computermanaged instruction. College Student Journal, 31, 490-495.

26. Roblyer, M. (1999). Is choice important in distance learning? A study of student motives for taking Internet-based courses at the high school and community college levels. Journal of Research on Computing in Education, 32 (1), 157-71.

27. Rossman, M. (2000). Andragogy and distance education: Together in the new millennium. New Horizons in Adult Education, 14(1), 3-9. Retrieved from http://www.nova.edu/ aed/horizons/vol14n1.htm

28. Shin, M. \& Lee, Y. (2009). Changing the landscape of teacher education via online teaching and learning. Techniques: Connecting Education \& Careers, 83 (9), p. 32-33.

29. Smith, R.O. (2008). The paradox of trust in online collaborative groups. Distance Education, 29 (3), p. 325- 340.

30. Terry, N. (2001). Assessing enrollment and attrition rates for the online MBA. T.H.E. Journal, 28 (7), 6468.

31. Wahlstedt, A., Pekkola, S., \& Niemela, M. (2008). From e-learning space to e-learning place. British Journal of Educational Technology, 39 (6), p. 1020- 1030. 


\section{Appendix A - Online Education and Perception Survey}

Part I: Demographic Questionnaire

What is your gender?
1. Male 2
Female

A. What is your age?

1.

$2 . \quad 26-35$

3. $\quad 36-45$

4. $\quad 46-55$

5. 56 -above

B. How would you describe yourself?

1. W__ White, not of Hispanic origin?

2.___ Black, not of Hispanic origin?

3. Hispanic

4. Asian/Pacific Islander

5. __ American Indian/Alaskan Natives

6. __ Other (please specify)

C. What is the highest academic schooling you have acquired?

1. __ High school diploma or equivalent

2. T_ Two years of college, community college, or institute training

3. ___ Bachelors Degree

D. How long have you worked with your current employer?
1. L__Lss than one year
2 . $1-5$ years
3. $6-15$ years
4. Currently unemployed

E. What program are you in?
1. ___ Pharmacy Technician
2. _ Criminal Justice
3. Medical Assisting
4. ___ Dental Assisting

\section{Part II: Online Education Survey}

1. How often do you use a computer?
1.___Everyday
2. ___ Every other day
3. Once a week
4. ___ Other

2. Do You Have Your Own Computer?
1. Yes
2. No

3. Do You Have Your Own Internet Service Provider (internet access)?
1 . Yes
2. No

4. Where would you mainly access your online class from?
1. From home
$2 . \quad$ From school
3. $\quad$ From office (work)
4. From home and school 
5. Rate your proficiency with computers:

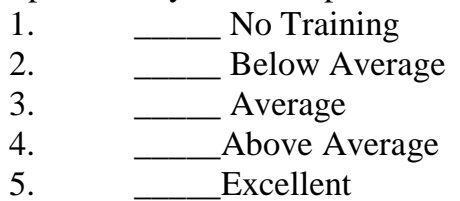

6. Rate your proficiency with the internet:
1. No Training
2. _ Below Average
3. _ Average
4. _ Above Average
5. __ Excellent

7. Do You Have enough Motivation and Ability to Work Independently?
1 . Yes
2. No

8. Do You Have enough Time for Online Work?
1 .
Yes
2. No

9. How are your time-management skills?
1.
2.
3.
5. No Time-Management skills Below Average Average Above Average Excellent

4.

10. Have you ever taken an online class before?
1. Yes
2. No

11. Would you like having the option of taking classes online?
1. Yes
2. No

12. Would you be content with taking all of your classes online?
1. Yes
2. No

13. Would you be willing to do group-work in an online setting?
1. Yes
2. No

14. What is your biggest concern about online education?
1. Will not learn as much
2. - No face-to-face interaction
3. - No support
4. _ _ No frequent feedback
5. _ _ Too many distractions

15. Would your online education be more effective if there was a computer lab on campus with tutors to assist you?
1.___ Yes
2. No

Comments: Write any of your thoughts, suggestions and concerns below. 
Table 2 - Regression Results for Online Characteristics Demographic Variables

\begin{tabular}{|c|c|c|c|c|c|c|c|c|c|}
\hline \multirow{2}{*}{\multicolumn{2}{|c|}{ Dependent Variables }} & & \multirow[b]{2}{*}{ Intercept } & \multirow[b]{2}{*}{ Gender } & \multirow[b]{2}{*}{ Age } & \multirow[b]{2}{*}{ Ethnicity } & \multicolumn{3}{|c|}{ Employmen } \\
\hline & & & & & & & Education & $\mathbf{t}$ & Program \\
\hline \multirow[t]{2}{*}{ Q1 } & Frequency of Computer Use & t-stat & 1.360 & -0.017 & -0.015 & 0.081 & 0.365 & -0.101 & -0.022 \\
\hline & & $\mathrm{p}$-value & $0.006 * * *$ & 0.903 & 0.916 & 0.086 & $0.048 * *$ & $0.101 *$ & 0.635 \\
\hline \multirow[t]{2}{*}{ Q2 } & Computer Ownership & t-stat & 1.130 & -0.048 & 0.071 & 0.043 & -0.007 & -0.026 & 0.021 \\
\hline & & $\mathrm{p}$-value & $0.000 * * *$ & 0.429 & 0.244 & $0.031 * *$ & 0.925 & 0.309 & 0.293 \\
\hline \multirow[t]{2}{*}{ Q3 } & Own Internet Service & t-stat & 1.503 & -0.036 & -0.010 & -0.033 & 0.049 & -0.049 & -0.020 \\
\hline & & $\mathrm{p}$-value & $0.000 * * *$ & 0.543 & 0.866 & $0.099 *$ & 0.523 & $0.054 *$ & 0.306 \\
\hline \multirow[t]{2}{*}{ Q4 } & Internet Access Location & t-stat & 1.408 & 0.155 & -0.278 & 0.009 & 0.503 & 0.153 & -0.112 \\
\hline & & $\mathrm{p}$-value & $0.017 * *$ & 0.368 & $0.106^{*}$ & 0.871 & $0.022 * *$ & $0.037 *$ & 0.046 \\
\hline \multirow[t]{2}{*}{ Q5 } & Computer Proficiency & t-stat & 3.875 & -0.070 & -0.129 & -0.030 & 0.121 & -0.090 & 0.022 \\
\hline & & $\mathrm{p}$-value & $0.000 * * *$ & 0.563 & 0.287 & 0.456 & 0.435 & $0.080 *$ & 0.578 \\
\hline \multirow[t]{2}{*}{ Q6 } & Internet Proficiency & t-stat & 4.323 & 0.043 & -0.352 & 0.073 & -0.167 & -0.089 & -0.018 \\
\hline & & p-value & $0.000 * * *$ & 0.719 & $0.004 * * *$ & $0.067 *$ & 0.280 & $0.083 *$ & 0.653 \\
\hline \multirow[t]{2}{*}{ Q7 } & Motivation for Independent Study & t-stat & 1.541 & -0.079 & 0.100 & -0.056 & -0.054 & -0.041 & -0.019 \\
\hline & & $\mathrm{p}$-value & $0.000 * * *$ & 0.141 & $0.063 *$ & $0.002 * * *$ & 0.428 & $0.075 *$ & 0.276 \\
\hline \multirow[t]{2}{*}{ Q8 } & Time for Online Study & t-stat & 1.282 & 0.097 & -0.057 & -0.015 & -0.110 & 0.052 & 0.026 \\
\hline & & $\mathrm{p}$-value & $0.000 * * *$ & 0.164 & 0.412 & 0.501 & 0.216 & $0.076^{*}$ & 0.250 \\
\hline \multirow[t]{2}{*}{ Q9 } & Time Management Skills & t-stat & 3.418 & 0.041 & -0.279 & 0.028 & -0.076 & 0.049 & -0.002 \\
\hline & & $\mathrm{p}$-value & $0.000 * * *$ & 0.776 & $0.051 * *$ & 0.556 & 0.676 & 0.423 & 0.966 \\
\hline \multirow[t]{2}{*}{ Q10 } & Online Course Experience & t-stat & 1.830 & 0.093 & -0.009 & 0.006 & -0.135 & 0.019 & -0.014 \\
\hline & & $\mathrm{p}$-value & $0.000 * * *$ & $0.079 *$ & 0.858 & 0.717 & $0.047 * *$ & 0.398 & 0.406 \\
\hline \multirow[t]{2}{*}{ Q11 } & Online Class Option & t-stat & 1.368 & 0.048 & -0.058 & 0.025 & -0.099 & 0.063 & -0.027 \\
\hline & & $\mathrm{p}$-value & $0.000 * * *$ & 0.499 & 0.412 & 0.283 & 0.273 & $0.038 * *$ & 0.237 \\
\hline \multirow[t]{2}{*}{ Q12 } & All Classes Online & t-stat & 1.616 & 0.123 & -0.135 & 0.026 & -0.005 & 0.000 & 0.006 \\
\hline & & $\mathrm{p}$-value & $0.000 * * *$ & $0.059 *$ & $0.038 * *$ & 0.224 & 0.953 & 0.998 & 0.765 \\
\hline \multirow[t]{2}{*}{ Q13 } & Online Group Work & t-stat & 1.747 & 0.123 & -0.150 & 0.022 & -0.194 & -0.004 & -0.005 \\
\hline & & $\mathrm{p}$-value & $0.000 * * *$ & $0.083^{*}$ & $0.034 * *$ & 0.346 & $0.032 * * *$ & 0.898 & 0.816 \\
\hline \multirow[t]{2}{*}{ Q14 } & Biggest Concern for Online Study & t-stat & 2.566 & -0.158 & 0.141 & -0.053 & 0.206 & 0.013 & 0.044 \\
\hline & & p-value & $0.000 * * *$ & 0.450 & 0.498 & 0.441 & 0.439 & 0.881 & 0.512 \\
\hline \multirow[t]{2}{*}{ Q15 } & Preference for Computer Lab & t-stat & 1.506 & 0.005 & -0.055 & -0.042 & -0.207 & 0.028 & 0.050 \\
\hline & And Tutors on Campus & $\mathrm{p}$-value & $0.000 * * *$ & 0.934 & 0.373 & $0.041 * *$ & $0.009 * * *$ & 0.279 & $0.013 * *$ \\
\hline
\end{tabular}

*Iimplies 90 percent confidence level, ** implies 95 percent confidence level, *** implies 99 percent confidence level 
Table 3 - Summary of Significant Findings

\begin{tabular}{|c|c|c|c|c|c|c|c|}
\hline Dependent Variables & Intercept & Gender & Age Group & Ethnicity & Education & Employment & Program \\
\hline Frequency of Computer Use & Sig. & & & & Sig & Sig & \\
\hline Computer Ownership & Sig. & & & Sig. & & & \\
\hline Own Internet Service & Sig. & & & Sig. & & Sig. & \\
\hline Internet Access Location & Sig. & & Sig. & & Sig. & Sig. & \\
\hline Computer Proficiency & Sig. & & & & & Sig. & \\
\hline Internet Proficiency & Sig. & & Sig. & Sig. & & Sig. & \\
\hline Motivation for Independent Study & Sig. & & Sig. & Sig & & Sig. & \\
\hline Time for Online Study & Sig. & & & & & Sig. & \\
\hline Time Management Skills & Sig. & & Sig. & & & & \\
\hline Online Course Experience & Sig. & Sig. & & & Sig. & & \\
\hline Online Class Option & Sig. & & & & & Sig. & \\
\hline All Class Online & Sig. & Sig. & Sig. & & & & \\
\hline Online Group Work & Sig. & Sig. & Sig. & & Sig. & & \\
\hline Biggest Concern for Online Study & Sig. & Sig. & Sig. & & Sig. & & \\
\hline Preference for Computer Lab & Sig. & & & Sig. & Sig. & & Sig. \\
\hline
\end{tabular}


NOTES 